\title{
Crustacean fundamentals
}

\author{
Michal Grabowski \\ Department of Invertebrate Zoology \& Hydrobiology, University of Lodz, Banacha 12/16, 90-237 Lodz, Poland
}

Review of Treatise on Zoology - Anatomy, Taxonomy, Biology - The Crustacea, Volume 2, edited by J. Forest and J.C. von Vaupel Klein. Advisory Editor: F. R. Schram. Brill, Leiden-Boston, 2006, 552 pp., ISBN13: 978900413791 2, ISBN-10: 9004137912

The series "Traité de zoologie, anatomie, systématique, biologie" was founded in 1950 and edited for a long time by the late Pierre-Paul Grassé, a famous French zoologist. Since the beginning, 17 volumes with some 40 fascicles have been published in French, covering nearly the entire protist and animal world, from heterotrophic unicellular organisms to mammals. Through all the years the series was known to include very high quality papers on anatomy and several aspects of organismal biology, many of fundamental meaning for specialist in the corresponding fields. Volume VII, encompassing three parts, published originally in 1994, 1996 and 1999, was devoted entirely to Crustacea. Now, thanks to the brilliant initiative of the Brill publisher (being anyway among the most prominent publishers in the field of carcinology) the volume has been being translated to English, to make it accessible to even wider international scientific community. To assess the quality of the work, it is enough to say that the editor of the original French edition, Jacques Forest has been contracted as a supervisory editor, the translation has been done principally by J. Carel von Vaupel Klein, and Frederic R. Schram has served as an advisory editor for the series. The original three parts of Volume VII have been split up to 9 volumes in English edition. The first four are intended to include general chapters on various aspects of crustacean anatomy and biology from segmentation and the integument, through sense organs and their functioning, anatomy and physiology of circulatory, digestive, endocrine, neural and reproductive systems to issues on embryology, growth, genetics and place of crustaceans in the biosphere. The volumes 5 to 9 will cover systematics and classification of all crustacean groups. As some of the original texts date already to early 1980 s, all the chapters have been reviewed and updated by the original authors or, if not possible, by other prominent specialist in the respective fields. Almost all the volumes will also contain new contributions.

The volume 2 comprises of five chapters originating from the French edition on: the circulatory system, the digestive tract: anatomy, physiology, and biochemistry, osmoregulation: morphological, physiological, biochemical, hormonal, and developmental aspects, the endocrine organs, the ontogeny of sex and sexual physiology. The sixth chapter, dealing with the origins of crustacean larvae, is a completely new contribution. Each chapter has its own bibliography section and the whole book ends with a list of contributors, as well as with both taxonomic and subject indices.

The first chapter, by Mayrat, McMahon and Tanaka, describes in great details the circulatory system starting wisely with a couple of pages covering the basics, very useful for those of us, for which anatomy is not a daily bread. A very nice addition is a short critical review of methods used in studying the comparative and functional anatomy of the circulatory system. All the abbreviations used in the figures are also listed in this section. Then follows the hard anatomy part. The nonmalacostracans are treated first and divided in sections such as: Branchiopoda (exclusive of the Cladocera) and Branchiura, groups with a short heart or without heart (cladocerans, some copepods, ostracods), and the Cirripedia, followed by section on the electron microscope histology of the heart in these groups. Naturally, most of the chapter is devoted to malacostracans. Contrary to the former subchapter, the latter one is divided into sections describing particular structures (the heart, arterial systems, sinus system), followed by morphology and histology of the cardiovascular system, composition and functions of the haemolymph, the system innervation, physiology, and functional ontogeny. The last, very interesting section concerns the phylogenetic implication that can be drawn from the facts exposed throughout the chapter, with the two main conclusions - one against the validity of 
Peracarida, and the other supporting the concept of Podophthalmata.

The second chapter, authored by Cecaldi, is devoted to the digestive tract and unquestionably it is the longest and most detailed contribution in the presented volume. As the previous chapter it starts with some information of general nature, then followed by sections describing embryonic development, organogenesis and differentiation of the digestive system during larval development in various groups of Crustacea. Comparative anatomy of adult stages is presented for several non-malacostracan (Branchiopoda, Ascothoracida, Cirripedia, Copepoda, Ostracoda) and malacostracan (Leptostraca, Mysidacea, Isopoda, Amphipoda, Euphausiacea, Decapoda) groups. A separate, extensive section treats in details only the anatomy of the digestive tract in Decapoda. Another section presents microscopic anatomy of the digestive tube in Copepoda, Isopoda, Amphipoda and Decapoda, also in its ontogenetic and functional aspects. Large part of the text is devoted to the physiology and biochemistry of the digestion process. The influence of internal factors (moulting and reproductive cycles) and issues of the food detection are also discussed. The way of food particles along the digestive tract is presented in details, starting with mechanical degradation through enzymatic activities and intestinal bacterial flora and ending with the energy transfer after digestion. A very interesting review of ecophysiological variation of digestive function includes several ecological factors such as light, temperature and physical structure of the environment. Short sections upon the excretion processes, neural and hormonal control and emulsifying agents, followed by a more applicatory subchapter upon nutrition of crustaceans in aquacultures, concluded this very exhaustive chapter. At the end, a very useful appendix is provided listing all the species of Crustacea used in the chapter with their authorities and classifications.

The third chapter co-authored by Pequeux, Dandrifosse, Loret, Charmantier, Charmantier-Daures, Spanings-Pierrot and late Schoffeniels reviews morphological, physiological, biochemical, hormonal and developmental aspects of osmoregulation. Overall the chapter is divided into five parts, with the part E containing only the references. Part A describes mainly the macroscopic and microscopic anatomy as well as physiology of excretory organs and gills. The former are exemplified with several taxa, such as Artemia, Balanus, Corophium, Procambarus, Uca, etc. The gills, on the other hand, are characterized based exclusively upon decapods. The part includes also a very interesting section on responses of crustaceans to variations in environmental salinity - a basic ecophysiological problem faced by a majority of crustacean species. Part B deals with the neuroendocrine control of osmoregulation, and part $\mathrm{C}$ with the specifics of the osmoregulatory process in various stages of ontogenic development. A concise part D presents shortly and rather superficially the evolutionary aspects of osmoregulation. In fact it only addresses some major evolutionary steps in urea and amino acid metabolism without a detailed discussion.

The following chapter by Charmantier-Daures and Charmantier concentrates on the anatomy and ultrastructure of endocrine organs, which functions and effects were touched several times, more or less extensively, in the preceding papers. In fact it would be even more logical if the chapter was reordered with the next one, due to the regulatory position of endocrine organs over all the other systems. An interesting tip in this chapter are subsections upon the history of studies and species used in case of particular organs. Following the literature section, the paper is supplied with an appendix containing all the scientific names and classification of mentioned taxa.

The one but last chapter is authored by Legrand and Juchault. It describes in details the ontogeny of sex and sexual physiology in Crustacea. First, the anatomy and function of androgenic gland is presented followed by the differentiation of gonads and all kind of aspects related to humoral control and secondary sexual differentiation in both sexes. A very nice part addresses the sex determination issues, including apart of genetic mechanisms, also an influence of epigenetic factor on sex determination. Broadly discussed are sexual anomalies, such as intersexuality and monogeny over quite a broad range of crustacean taxa. Parthenogenesis and hermaphroditism with short subsections discussing place of this phenomena in the evolution of sex close this chapter.

The ultimate chapter is a completely new contribution from Williamson. According to its title it presents the origin of crustacean larvae. Inclusion of such subject in a volume devoted predominantly to crustacean internal structures and physiology is quite surprising, as the paper stands out from this otherwise very uniform publication. In fact the paper does not deal that much with elucidating the origins of larval forms in Crustacea. Basically, it is a review of morphology of the basic larval forms occurring in the course of development in various crustacean taxa, with some limited 
discussion concerning the use of larval forms in classification of Crustacea. It is disappointing that only one hypothesis (larval transfer) on the evolution of larval stages is reported, and this even shortly. Taking into account the rather broad literature concerning invertebrates in general and marine larvae in particular, the chapter could have been expected to discuss the issue in more details to stand up to its title.

Summarizing, the entire volume is an impressive collection of papers, mostly illustrated with very good quality figures, including drawings as well as microphotographs. It contains also a vast collection of references, definitely of great importance for all researchers in the field. As most of the standard books on Crusta- cea (Th. Waterman's The Physiology of Crustacea, D.E. Bliss' The Biology of Crustacea, and F.R. Schram's Crustacea) are currently getting slightly outdated, and of course for the outstanding quality of the volume itself, there is no doubt that "The Crustacea" will become a very important reference book not only for carcinologists but also for academic teachers lecturing invertebrate zoology for whom the book is an extremely rich source of knowledge and the figures are just ready to use as illustrations of their courses.

Received: 17 January 2008

Accepted: 18 January 2008 
